\title{
Analisis Terhadap Kualitas Air Sungai Kaligarang sebagai Sumber Air Baku PDAM
}

\author{
Natasha Cindy Kardia Etnovanese', Tiyas Matilda Aprillia², Dr. Ir. Djoko Suwarno, M.Si ${ }^{3}$, Ir. \\ D. Budi Setiyadi, MT. ${ }^{4}$ \\ e-mail: natashacindy14@gmail.com ${ }^{1}$ \\ ${ }^{1,2}$ Mahasiswa Program Studi Teknik Sipil, Fakultas Teknik, Universitas Katolik Soegijapranata; \\ Jalan Pawiyatan Luhur IV Nomor 1, Bendan Dhuwur, Kota Semarang, (024)8441555 \\ ${ }^{3,4}$ Dosen Program Studi Teknik Sipil, Fakultas Teknik, Unika Soegijapranata, Semarang
}

\begin{abstract}
The usage of water should be wisely. Water which most used by the community is river water. Kaligarang river water is used for irrigation, to wash the clothes, cleanse sewage. and as the basic source of PDAM Tirta Moedal Semarang. This observation method is literature study, collect data by interview and take the water sample, and analysis the water quality. The observation of water quality is done to search for the cause of Kaligarang river pollution so that we know how to neutralize the river basic source in PDAM Tirta Moedal Semarang. The observation is done in the draught season because at this time the content of pollution is higher. The water sample is taken from the river junction, back of PDAM TM intake, and at the estuary. The quality criteria of water is based on PPRI number 82, 2001. The result shows that water at every spot has parameter which higher. Has high value parameter which is more than the limitation value which is different and the pollutant is much in the muara. The penetrate used by PDAM Tirta Moedal is chlorin and tawas, and the usage doesn not influent the cost of production nor distribution but it causes the production process stop, so that the people should have water containers at their homes.
\end{abstract}

Keywords: Water quality,excessive contamination, Kaligarang river water, basic source, PDAM

\section{Pendahuluan}

Air merupakan sumber daya alam yang berlimpah di muka bumi. Komponen bumi yaitu 97,2 \% adalah air (Ambarwati, 2014). Persebaran air di muka bumi mencapai volume sebesar 1.386 juta $\mathrm{km}^{3}(70,8 \%)$ dan dari total jumlah air di bumi. Jumlah air yang berlimpah tersebut dapat dimanfaatkan oleh makhluk hidup.

Menurut Effendi (2003), pemanfaatan air perlu diimbangi dengan kebijaksanaan dalam penggunaannya sehingga dapat dimanfaatkan seluruh makhluk hidup. Makhluk hidup terutama manusia memiliki berbagai kegiatan yang memerlukan air. Air dibutuhkan manusia untuk minum, mandi, dan mencuci. Air yang dimanfaatkan manusia tersedia di danau, sungai, dan di sumur dangkal. Pemanfaatan air secara bijaksana dilakukan supaya air dapat dimanfaatkan oleh generasi mendatang.

Air yang banyak dimanfaatkan oleh manusia berasal dari air sungai. Menurut Peraturan Pemerintah no. 35 tahun 1991, air sungai merupakan air yang berada tempat-tempat dan wadah-wadah serta jaringan pengaliran air mulai dari mata air sampai muara dengan dibatasi kanan dan kirinya serta sepanjang pengalirannya oleh garis sempadan. Jawa Tengah memiliki sungai bernama Sungai Kaligarang yang memiliki mata air di Desa Gebugan, Kecamatan Bergas, Kabupaten Semarang dan memiliki 
muara yang terletak di Kelurahan Tanah Mas, Kecamatan Semarang Utara, Kota Semarang. Masyarakat Kota Semarang sangat bergantung pada air Perusahaan Daerah Air Minum (PDAM), dan Sungai Kaligarang merupakan sumber air baku di PDAM Tirta Moedal Semarang. Maka dari itu kualitas air Sungai Kaligarang harus dijaga supaya minim pencemaran.

Menurut Yulianti 2010, Sungai Kaligarang adalah sungai terbesar di daerah Kota Semarang. Sungai ini merupakan bagian dari tiga sungai utama Daerah Aliran Sungai (DAS) yaitu Sungai Kaligarang, Sungai Kripik, dan Sungai Kreo. Kaligarang dimanfaatkan sebagai bahan baku air minum oleh PDAM Tirta Moedal Kota Semarang. Peraturan Gubernur Jawa Tengah No. 156 tahun 2010, Sungai Kaligarang dibagi dalam 7 segmen yang terdiri dari:

1. Segmen I

Sungai Kaligarang yang dimulai dari daerah hulu Desa Gebugan, Kecamatan Bergas, Kabupaten Semarang sampai dengan Kelurahan Pudak Payung, Kecamatan Banyumanik, Kota Semarang. Panjang Sungai pada segmen I sekitar 12,2 km. Di segmen ini terdapat kegiatan pertanian dan perkebunan, industri, peternakan serta pemukiman yang berpotensi mencemari Sungai Kaligarang. Kegiatan Industri yang berada di segmen ini diantaranya adalah PT. Batamatex, PT. Nissin Biscuit dan PT. Pepsi Cola.

\section{Segmen II}

Sungai Kaligarang yang dimulai dari Kelurahan Pudak Payung, Kecamatan Banyumanik, Kota Semarang sampai dengan Kelurahan Bendan Duwur, Kecamatan Gajah Mungkur, Kota Semarang. Segmen II sebagian besar wilayahnya berada di Kecamatan Banyumanik yang berada di Kota Semarang. Panjang sungai pada segmen ini sekitar $11,5 \mathrm{~km}$. Kegiatan yang berpotensi meningkatkan beban pencemaran sungai di sepanjang segmen ini diantaranya adalah industri (PT. Raja Besi, PT. Jamu dan Farmasi Cap Jago, dan PT. Kubota Indonesia) serta kegiatan pemukiman.

3.Segmen III

Sungai Kaligarang yang dimulai dari bagian Timur Kelurahan Bendan Duwur, Kecamatan Gajah Mungkur, Kota Semarang sampai dengan bagian Barat Kelurahan Bendan Duwur, Kecamatan Gajah Mungkur, Kota Semarang. Segmen III meliputi wilayah Kecamatan Banyumanik, Gajah Mungkur dan Ngaliyan. Pada Segmen ini panjang sungai hanya $2,4 \mathrm{~km}$. Di segmen ini sebagian besar lahan merupakan pemukiman dan lahan pertanian.

4.Segmen IV

Sungai Kreo yang dimulai dari Kelurahan Polaman, Kecamatan Mijen, Kota Semarang sampai dengan Kelurahan Sadeng, Kecamatan Gunung Pati, Kota Semarang. Segmen IV merupakan sub DAS Kreo yang meliputi wilayah Kabupaten Semarang, Kabupaten Kendal dan Kota Semarang. Di segmen ini terdapat kegiatan pertanian dan perkebunan, indsutri, TPA sampah, serta pemukiman yang berpotensi mencemari sungai. Panjang sungai pada segmen ini sekitar $15,5 \mathrm{~km}$.

5.Segmen V

Sungai Kaligarang yang dimulai dari Kelurahan Sadeng, Kecamatan Gunung Pati, Kota Semarang sampai dengan Kelurahan Bendan Duwur, Kecamatan Gajah Mungkur, Kota Semarang. Segmen V merupakan sub DAS Kripik yang terdiri dari Kecamatan Ungaran Barat, Ngaliyan, dan Gunung Pati dengan panjang sungai sekitar $2,6 \mathrm{~km}$.

6.Segmen VI

Sungai Kaligarang yang dimulai dari Kelurahan Bendan Duwur, Kecamatan Gajah Mungkur, Kota Semarang sampai dengan Kelurahan Barusari, Kecamatan Semarang Selatan, Kota Semarang. 
Segmen VI meliputi wilayah Kecamatan Banyumanik, Semarang Selatan, Semarang Barat, Gajah Mungkur, dan Candisari. Di Segmen ini terdapat pengambilan air baku PDAM Kota Semarang. Di samping itu terdapat pula kegiatan industri PT. Alam Daya Sakti, PT. Kimia Farma, PT. Semarang Makmur, PT. Damaitex, PT. Sinar Pantja Djaya, PT. Phapros, kegiatan pemukiman serta Rumah Sakit Karyadi. 7.Segmen VII

Sungai Banjir Kanal Barat yang dimulai dari Kelurahan Barusari, Kecamatan Semarang Selatan, Kota Semarang sampai dengan Kelurahan Panggung Lor, Kecamatan Semarang Utara, Kota Semarang. Segmen VII meliputi wilayah Kecamatan Banyumanik, Semarang Selatan, Semarang Utara, Semarang Tengah dan Semarang Barat. Pada segmen ini terdapat kegiatan pemukiman, industri kecil seperti tahu dan tempe serta pengolahan ikan.

Penelitian ini merupakan penelitian payung dari dana Menristek-Dikti oleh Hadipuro dkk, 2018 dengan judul "Membangun Pengelolaan Sungai Berjejaring Melalui Teknologi Informasi Dan Komunikasi”.

Tujuan jangka panjang penelitian ini adalah memberikan kontribusi untuk manajemen sumber daya air di PDAM Tirta Moedal Kota Semarang. Pemanfaatan air Sungai Kaligarang perlu dimanajemen mengingat aliran anakanak Sungai Kaligarang mendapatkan beban pencemaran. Beban pencemaran tersebut berasal dari aktivitas perkampungan, pabrik dan industri, rumah makan, apotek, pertanian, dan perikanan. Beban pencemaran yang semakin banyak mempengaruhi biaya pengolahan air baku di PDAM Tirta Moedal Kota Semarang dan biaya air PDAM tersebut ke masyarakat.

\subsection{Tujuan Penelitian}

Tujuan dari penelitian ini:

1. Mengetahui sumber pencemar air Sungai Kaligarang pada segmen 6 dan 7 ,

2. Mengetahui kualitas air Sungai Kaligarang Kota Semarang sehingga dapat ditentukan penetralisir yang digunakan untuk proses pengolahan air baku PDAM Tirta Moedal Kota Semarang.

\subsection{Manfaat Penelitian}

Tugas akhir ini diharapkan dapat bermanfaat sebagai:

1. Penerapan Ilmu Rekayasa Lingkungan Teknik Sipil yang telah didapat selama proses perkuliahan,

2. Informasi terkait kualitas air Sungai Kaligarang terhadap perawatan air PDAM Kota Semarang,

3. Masukkan yang dapat digunakan oleh instansi pemerintah dalam menjaga kualitas air Sungai Kaligarang sehingga teraturnya kebutuhan biaya perawatan dan bahan pengolahan air PDAM.

\subsection{Batasan Masalah}

Tugas akhir ini memiliki batasanbatasan masalah yang ditentukan yaitu:

1. Karakteristik kualitas air Sungai Kaligarang diambil pada musim kemarau dengan data laboratorium, karena konsentrasi polutan dalam air pada musim kemarau lebih tinggi dibandingkan pada musim penghujan,

2. Pengamatan cara pengolahan air yang dilakukan PDAM Tirta Moedal Kota Semarang,

3. Uji laboratorium yang dilakukan hanya kualitas air saja.

\subsection{Sistematika Penulisan}

Sistematika penulisan tugas akhir ini adalah sebagai berikut: 
1. Bab I: Pendahuluan

Berisi tentang latar belakang, tujuan penulisan, manfaat penulisan, batasan penelitian, dan sistematika penulisan.

2. Bab II: Tinjauan Pustaka

Berisi tentang teori-teori pendukung dalam Pembuatan Tugas Akhir ini.

3. Bab III: Metode Penelitian

Berisi tentang lokasi penelitian, tahap penelitian, alat dan bahan yang digunakan, jadwal penelitian, dan bagan alir penelitian.

4. Bab IV: Hasil dan Pembahasan

Berisi tentang analisis yang dilakukan untuk mencapai maksud dan tujuan penelitian ini.

5. Bab V: Penutup

Berisi tentang kesimpulan yang merupakan rangkuman hasil-hasil yang berasal dari pembahasan secara rinci dan saran-saran atau rekomendasi.

\section{Tinjauan Pustaka}

Air adalah salah satu senyawa kimia yang ketersediaannya di alam sungguh berlimpah (Effendi, 2003). Air baku atau raw water adalah bahan utama dalam hal proses penyediaan air bersih. Sedangkan untuk pengertian air baku sendiri adalah air yang berasal dari sumber air permukaan, cekungan air tanah dan atau air hujan yang memenuhi ketentuan baku mutu tertentu sebagai air baku untuk air minum (SNI 6674, 2008).

\subsection{Sumber Air}

Sebagai sumber daya alam yang sangat dibutuhkan oleh semua makhluk hidup, air harus dilindungi dan dijaga kualitasnya agar dapat dimanfaatkan dengan baik oleh manusia serta makhluk hidup lain. Dalam pemanfaatannya harus dilakukan secara bijaksana, aspek penghematan dan pelestarian harus ditanamkan pada segenap pengguna air (Effendi, 2003).

Ada pula yang mengklasifikasikan sumber air menjadi tiga bagian, yaitu air permukaan, air angkasa, dan air tanah (Yulia, 2015).

\subsection{Sungai}

Sungai adalah air tawar dari sumber yang mengalir dari tempat yang lebih tinggi ke tempat yang lebih rendah dan bermuara ke laut, danau atau sungai yang lebih besar (Sari, 2016). Menurut Peraturan Pemerintah Nomor 35 Tahun 1991, sungai adalah tempat-tempat dan wadah-wadah serta jaringan pengalir air mulai dari mata air sampai muara dengan dibatasi kanan dan kirinya serta sepanjang pengalirannya oleh garis sempadan (garis batas luar pengaman sungai).

Sungai mengalir dari hulu dalam kondisi kemiringan lahan yang curam dan berturut-turut menjadi agak curam, agak landai dan relatif rata. Arus sungai relatif menjadi cepat di daerah hulu dan menjadi lambat pada daerah hilir. Sungai sebagai sumber air merupakan salah satu sumber daya alam yang mempunyai fungsi serba guna bagi kehidupan manusia. Menurut Mulyanto (2007) ada dua fungsi utama sungai secara alami yaitu mengalirkan air dan mengangkut sedimen hasil erosi pada DAS dan alurnya. Kedua fungsi ini terjadi bersamaan dan saling mempengaruhi.

\subsection{Perusahaan Daerah Air Minum}

Perusahaan Daerah Air Minum (PDAM) adalah badan usaha milik pemerintah daerah, yang melakukan pelayanan menghasilkan kebutuhan air minum atau air bersih bagi masyarakat, dan diharapkan dapat memberikan pelayanan akan air bersih yang merata kepada seluruh lapisan masyarakat serta menetapkan tarif yang sesuai dengan kemampuan masyarakat (Hartono, 2005). 


\subsubsection{Unit-unit Pengolahan Air Bersih}

Adapun unit-unit pengolahan air bersih terdiri dari (Sutrisno, 2006):

1. Bangunan penangkap air (intake) adalah suatu bangunan untuk menangkap air atau mengumpulkan air dari suatu asal air, untuk dapat dimanfaatkan. Bangunan penangkap air dilengkapi dengan bar screen yang berfungsi untuk mencegah masuknya sampah-sampah.

2. Bangunan prasedimentasi (pengendapan pertama) dalam pengolahan air ini berfungsi untuk mengendapkan partikel-partikel padat dari air sungai dengan gaya gravitasi. Pada proses ini tidak ada pembubuhan bahan kimia.

3. Bangunan pulsator koagulasi/pengendapan kedua) adalah bangunan untuk memberi tambahan koagulan secara teratur sesuai kebutuhan (dengan dosis yang tepat). Koagulan adalah bahan kimia yang dibutuhkan pada air untuk membantu proses pengendapan partikel-partikel kecil yang tidak dapat mengendap dengan sendirinya. Penambahan koagulan ke dalam air baku diukuti dengan pengadukan cepat yang bertujuan untuk mencampur antara koagulan dengan koloid.

4. Bangunan pengaduk cepat ini untuk meratakan bahan/zat kimia (koagulan) yang ditambahkan agar dapat bercampur dengan air secara baik, sempurna dan cepat.

5. Bangunan sedimentasi (pembentuk flok) berfungsi untuk membentuk partikel padat yang lebih besar supaya dapat diendapkan dari hasil reaksi partikel kecil (koloid) dengan bahan atau zat koagulan yang di bubuhkan.

6. Bangunan pengendap kedua berfungsi untuk mengendapkan flok yang berbentuk pada unit bak pembentuk flok.
7. Bangunan filtrasi (penyaringan) untuk menghilangkan zat tersuspensi yang terakhir adalah dengan filtrasi atau penyaringan. Proses filtrasi dimaksudkan untuk menyisihkan partikel kolois yang tidak dapat disisihkan pada proses sebelumnya dan juga untuk mengurangi jumlah bakteri organisme lain.

8. Reservoir (desinfeksi) adalah langkah terakhir pada pengolahan air mentah menjadi air bersih. Air yang mengalir dari filter ke reservoir dibubuhi chlor dengan tujuan untuk membunuh mikroorganisme pathogen. Desinfeksi dengan chlor di Indonesia kebanyakan digunakan kaporit $\mathrm{Ca}(\mathrm{OCl} 2)$ karena murah, mudah didapat, dan mudah penanganannya.

9. Pompa Air Bersih (pemompaan) berfungsi untuk mendistribusikan air bersih dari reservoir instalasi ke reservoir-reservoir distribusi cabangcabang melalui pipa-pipa transmisi yang dibagi menjadi 5 jalur dengan kapasitas 150 l/detik.

10. Lagoon berfungsi untuk menampung semua air buangan bekas pencucian sistem pengolahan untuk di daur ulang dan kemudian di alirkan kembali ke Bak Air Baku untuk diproses kembali.

\subsection{Klasifikasi Mutu Air}

Setiap kebutuhan memiliki standar mutu air yang berbeda, sebagai contohnya standar mutu air untuk irigasi pasti berbeda dengan standar mutu air untuk dikonsumsi (Alaudin, 2016).

Klasifikasi dan kriteria kualitas air di Indonesia diatur dalam Peraturan Pemerintah Republik Indonesia Nomor 82 Tahun 2001. Berdasarkan Peraturan Pemerintah tersebut, kualitas air diklasifikasikan menjadi empat kelas yaitu: 
1. Kelas satu, air yang peruntukkannya digunakan sebagai air baku air minum,

2. Kelas dua, air yang peruntukkannya digunakan sebagai prasarana/sarana rekreasi, pembudidayaan ikan air tawar, peternakan, dan air untuk mengairi tanaman,

3. Kelas tiga, air yang peruntukkannya digunakan sebagai pembudidayaan ikan air tawar, peternakan, dan air untuk mengairi tanaman,

4. Kelas empat, air yang peruntukkannya digunakan sebagai air yang mengairi tanaman.

\subsection{Pencemaran Air}

Menurut Peraturan Pemerintah Republik Indonesia No. 20 tahun 1990 tentang Pengendalian Pencemaran Air, pencemaran air adalah masuk atau dimasukkannya makhluk hidup, zat, energi, dan atau komponen lain ke dalam air oleh kegiatan manusia sehingga kualitas air menurun dan tidak dapat berfungsi sesuai dengan peruntukkannya.

Dalam suatu keadaan yang banyak terjadi pencemaran air, maka perlu dilakukan pengendalian pencemaran air yang berupa tindakan pencegahan dan atau penanggulangan dan atau pemulihan. Menurut Peraturan Pemerintah Republik Indonesia No. 20 tahun 1990, kegiatan pengendalian tersebut meliputi:

a. Inventarisasi kualitas dan kuantitas air dalam sumber air, menurut sistem wilayah tata pengairan.

b. Penetapan golongan air menurut peruntukkannya, baku mutu air, dan baku beban pencemaran untuk golongan air tersebut, serta baku mutu limbah cair untuk setiap jenis kegiatan.

c. Penetapan mutu limbah cair yang boleh dibuang ke dalam air pada sumber air oleh setiap kegiatan dan pemberian izin pembuangannya.

d. Pemantauan perubahan kualitas air pada sumber air dan evaluasi hasilnya.

e. Pengawasan terhadap penataan peraturan pengendalian pencemaran air, termasuk penataan mutu limbah cair serta penegakkan hukumnya.

\subsection{Lokasi Penelitian}

Penelitian Tugas Akhir ini dilakukan dengan mengambil objek Sungai Kaligarang. Sungai Kaligarang memiliki hulu yang terletak di Desa Gebugan, Kecamatan Bergas, Kabupaten Semarang dan memiliki muara yang terletak di Kelurahan Panggung Lor, Kecamatan Semarang Utara, Kota Semarang. Kualitas air Sungai Kaligarang sangat menentukan kesehatan masyarakat, hal ini disebabkan karena aliran air yang mengalir di Sungai Kaligarang digunakan sebagai sumber salah satunya oleh Perusahaan Daerah Air Minum (PDAM) Tirta Moedal Kota Semarang. Penelitian yang berjudul "Analisis Terhadap Kualitas Air Sungai Kaligarang sebagai Sumber Air PDAM" ini menganalisis kualitas air di Sungai Kaligarang yang digunakan sebagai sumber air PDAM untuk wilayah Kota Semarang.

\subsection{Tahap Penelitian}

Penelitian Tugas Akhir ini memiliki beberapa tahapan, yaitu:

1. Studi literatur,

2. Tahapan pengumpulan data,

3. Pengolahan data analisis kualitas air di beberapa titik yang telah ditentukan di Sungai Kaligarang pada segmen 6 dan 7 .

\subsubsection{Studi literatur}

Studi ini mengambil beberapa referensi dari jurnal, buku, dan data sekunder dengan melakukan wawancara dengan pelaksana pengolahan air baku 
PDAM Tirta Moedal Kota Semarang. Akhir dari studi literatur ini, penelitian ini diharapkan sesuai dengan judul yang dibuat dan referensi yang diambil dari beberapa literatur.

\subsubsection{Pengumpulan data}

Pengumpulan data dalam penelitian ini menggunakan data primer dan data sekunder. Beberapa data yang dibutuhkan dalam penelitian ini, antara lain:

1. Data primer adalah data yang akan diolah untuk penelitian, diperoleh langsung dari lapangan atau wawancara, bukan dari pihak lain atau pihak ketiga (Windansari, 2013). Data primer dari penelitian ini berupa wawancara terhadap pelaksana pengolahan air di PDAM Tirta Moedal Kota Semarang dari hasil observasi lapangan dan hasil laboratorium uji kualitas air di Laboratorium Kesehataan Masyarakat (Labkesmas) Cito.

2. Data sekunder adalah data yang diperoleh secara tidak langsung oleh individu namun telah diolah lebih lanjut dan disajikan dengan baik oleh pihak pengumpul data primer atau pihak lain. Data sekunder berupa literatur, artikel, jurnal, dan situs di internet yang berkenaan dengan penelitian yang dilakukan. Data sekunder dari penelitian ini berupa data curah hujan, literatur, artikel, maupun jurnal yang mendukung penelitian ini.

\subsubsection{Pengolahan data}

Langkah awal dari penelitian ini yaitu dengan melaksanakan observasi lapangan. Narasumber yang diwawancarai yaitu pelaksana pengolahan air di PDAM Tirta Moedal Kota Semarang. Selanjutnya hasil wawancara tersebut diolah sehingga mendapatkan keadaan di lapangan. Data primer lainnya berupa hasil uji kualitas air Sungai Kaligarang melalui laboratorium yang diambil di beberapa titik pertemuan Sungai Kaligarang. Data kualitas air Sungai Kaligarang di beberapa tahun terakhir didapatkan melalui bank data lainnya sehingga memperlengkapi penelitian ini. Contoh data lain didapatkan dari Dinas Lingkungan Hidup yang melakukan pengujian kualitas air Sungai Kaligarang yang terdapat pada Lampiran B. Hasilhasil laboratorium tersebut dilengkapi dengan data curah hujan di DAS Sungai Kaligarang. Data curah hujan memberi perbedaan antara kualitas air yang berbeda antar musim kemarau dan musim hujan. Semua data tersebut menghasilkan kualitas air Sungai Kaligarang sebagai sumber air PDAM.

\subsection{Alat dan Bahan}

Penelitian tugas akhir ini membutuhkan alat dan bahan yang digunakan sebagai faktor penunjang untuk menyelesaikan laporan tugas akhir ini. Berikut alat dan bahan yang digunakan:

1. Buku,

2. Alat tulis,

3. Laptop,

4. Alat dokumentasi,

5. Alat transportasi,

6. Alat untuk pengambilan sampel air di Sungai Kaligarang,

7. Air di titik yang telah ditentukan di Sungai Kaligarang.

\subsection{Kondisi Fisik Daerah Penelitian}

\subsubsection{Sungai Kaligarang}

Menurut Windarta (2009), Sungai Kaligarang merupakan salah satu sungai terbesar di Kota Semarang. Sungai Kaligarang memiliki luas DAS $203 \mathrm{~km}^{2}$ dengan panjang dari hulu ke hilir \pm 35 $\mathrm{km}$. 
Sungai Kaligarang memiliki pola meranting karena memiliki anak-anak sungai seperti Sungai Kaligarang, Sungai Kreo, dan Sungai Kripik. Sungai Kaligarang memiliki berbagai fungsi bagi masyarakat yaitu untuk mencuci pakaian, mengairi sawah, dan menjadi air baku PDAM Tirta Moedal Semarang. Gambar 4.1 memperlihatkan aktivitas petani di sawah yang diairi oleh Sungai Kaligarang.

Sungai Kaligarang yang dimanfaatkan PDAM Tirta Moedal Semarang sebagai air baku, memiliki kantor induk yang berada di Jalan Kelud Raya No. 56 Semarang. PDAM tersebut memiliki visi menjadi penyedia air minum pilihan masyarakat. Menurut buku Company Profile PDAM Tirta Moedal Semarang, PDAM tersebut memiliki 167.979 pelanggan, maka dari itu Sungai Kaligarang menjadi sumber air yang penting di Kota Semarang.

\subsubsection{Kondisi Air Sungai Kaligarang}

Penelitian ini dilaksanakan dengan observasi lapangan yaitu kegiatan yang pertama adalah susur Sungai Kaligarang. Hasil dari kegiatan susur sungai yaitu mengetahui di beberapa titik sepanjang Sungai Kaligarang terdapat aktivitas masyarakat yang diperkirakan memberi beban pencemaran pada Sungai Kaligarang.

Observasi lapangan yang kedua dilaksanakan untuk menentukan titik pengambilan sampel. Titik pengambilan sampel telah ditentukan yaitu titik 1 adalah di daerah Tugu Suharto, titik 2 di belakang PDAM Tirta Moedal Semarang, dan titik 3 di muara Sungai Kaligarang. Titik pengambilan sampel ditentukan berdasarkan kebutuhan Penelitian ini yaitu di titik 1 adalah titik kumpul beban pencemaran dari hulu, Sungai Kreo dan Sungai Kripik. Titik 2 ditentukan di belakang PDAM Tirta
Moedal Semarang karena titik tersebut merupakan intake pengambilan sumber air baku PDAM tersebut. Titik 3 ditentukan di muara untuk mengetahui seberapa besar pengaruh beban-beban pencemaran dari hulu. Pelaksanaan pengambilan sampel atau observasi lapangan yang ketiga bertujuan untuk mengambil sampel dan mengobservasi air Sungai Kaligarang dengan membandingkan warna air tersebut dengan air mineral. Selain itu, sampel air diambil dengan jerigen yang dikirim ke Laboratorium Cito.

\subsubsection{Daerah Penelitian}

Penelitian ini mengacu pada air baku PDAM Tirta Moedal yaitu mengambil sampel di Sungai Kaligarang, maka data kualitas air lebih akurat. Kualitas air tersebut kemudian dijadikan bahan dalam proses pengolahan di PDAM Tirta Moedal Semarang. Data yang dianalisis meliputi tiga titik lokasi pengambilan sampel air.

Titik pertama berada di pertemuan air dari hulu, Sungai Kreo, dan Sungai Kripik yaitu di daerah Tugu Suharto. Pengambilan titik pertama di Tugu Suharto karena daerah tersebut merupakan daerah pemukiman dan ada berbagai macam industri di sekitar sungai. Selain itu daerah Tugu Suharto merupakan aliran sungai sebelum intake dari PDAM Tirta Moedal Semarang. Pengambilan sampel pada daerah ini yaitu pada koordinat $110^{\circ} 23^{\prime} 15^{\prime \prime} \mathrm{BT}$ dan $7^{\circ} 01^{\prime} 02,1^{\prime \prime} \mathrm{LS}$.

Titik yang kedua, pengambilan sampel air dilakukan di belakang PDAM Tirta Moedal Semarang karena di daerah ini merupakan aliran sungai yang terdekat dengan intake dari PDAM Tirta Moedal Semarang. Pengambilan sampel pada daerah ini yaitu pada koordinat $110^{\circ} 23^{\prime} 59,8^{\prime \prime} \mathrm{BT}$ dan $7^{\circ} 00^{\prime} 024,7^{\prime \prime} L S$. Gambar 4.8 merupakan titik daerah Sampangan Belakang PDAM. 
Pengambilan sampel air pada titik ketiga berada di bagian hilir dari Sungai Kaligarang yaitu di bagian muara yang mengarah ke laut. Pengambilan sampel pada daerah ini yaitu pada koordinat $110^{\circ} 23^{\prime} 52,7^{\prime \prime} \mathrm{BT}$ dan 657'16,2"LS.

\subsubsection{Kondisi Topografi}

Menurut Setyowati (2008), kondisi topografi merupakan tinggi rendahnya dataran yang ada di permukaan bumi dari permukaan laut dan ketinggian sungai yang ada. Kondisi topografi berpengaruh pada karakteristik ketinggian dan lama genangan atau banjir. Semakin tinggi wilayah dari permukaan laut dan sungai, maka wilayah tersebut akan cenderung tidak mengalami banjir. Topografi di daerah penelitian ini memiliki ketinggian ratarata 0 sampai 120 meter dari permukaan laut.

\subsubsection{Kondisi Geografi}

Menurut Fatahilah 2013, secara geografis Sungai Kaligarang terletak pada koordinat $110^{\circ} 18^{\prime} 28^{\prime \prime}-110^{\circ} 25^{\prime} 59^{\prime \prime}$ BT dan antara $6^{\circ} 56^{\prime} 46^{\prime \prime}-7^{\circ} 11^{\prime} 47^{\prime \prime}$ LS. Batas Sungai Kaligarang bagian utara berbatasan dengan Laut Jawa, sebelah Timur dengan Kabupaten Demak, selatan dengan Kabupaten Semarang, dan sebelah barat berbatasan dengan Kabupaten Kendal.

\subsubsection{Penggunaan Lahan}

Menurut Dewajati (2003), banyaknya peralihan fungsi penggunaan lahan menjadi lokasi pemukiman yang memadatkan tanah mempengaruhi lingkungan daerah hilir. Perubahan penggunaan lahan yang dilakukan di daerah hulu DAS juga memberikan dampak di daerah hilir dalam bentuk kenaikkan debit dan transpor sedimen dalam sistem aliran air. Namun menurut Peraturan Gubernur Jawa Tengah No. 156 tahun 2010, penggunaan lahan untuk kegiatan industri, pertanian, dan perkebunan di bagian hulu Sungai Kaligarang maka hilir Sungai Kaligarang memiliki dampak yaitu terdapat sedimen di beberapa titik di sepanjang Sungai Kaligarang.

\subsection{Kondisi Sosial}

Jumlah penduduk di sekitar Sungai Kaligarang sejumlah 253.083 jiwa pada 27 Kelurahan. Profesi atau mata pencaharian penduduk sangat bervariasi yaitu pedagang, pekerja kantor, guru dan pelaut atau nelayan. Pemukiman penduduk yang ada di sekitar Sungai Kaligarang cenderung padat, khususnya di daerah yang memusat atau mengarah ke pusat Kota Semarang.

Aktivitas di sekitar induk Sungai Kaligarang di bagian hulu adalah pertanian. Airnya cukup jernih dan beberapa penduduk memanfaatkan untuk mandi dan cuci. Industri yang membuang air limbahnya di sekitar daerah ini adalah industri pelapisan logam PT. Raja Besi. Terdapat pula RSUD Ungaran di dekat aliran Sungai Kaligarang serta beberapa tempat pendidikan di daerah tersebut.

Di dekat bagian hulu Sungai Kreo terdapat Tempat Pembuangan Akhir (TPA) Jatibarang yang merupakan tempat pembuangan sampah Kota Semarang. Setelah bergabung dengan Sungai Kreo dan Sungai Kripik, di Desa Pajangan (Tugu Suharto) debit Sungai Kaligarang menjadi besar. Aktivitas yang dilakukan di lokasi tersebut adalah penambangan pasir, pemukiman dan kegiatan industri. Industri tersebut yaitu PT. Semarang Makmur, PT. ISTW, PT. Kimia Farma, PT. Phapros, PT. Aldas, PT. Semarang Panca Jaya, PT. Damaitex, dan lain-lain.

Titik pengambilan sampel kedua merupakan daerah pemukiman dan peternakan, dan lokasi tersebut merupakan lokasi terdekat dari intake 
PDAM Tirta Moedal Semarang. Di lokasi tersebut air Sungai Kaligarang digunakan sebagai sumber air baku oleh PDAM Tirta Moedal Semarang untuk memenuhi kebutuhan air penduduk Kota Semarang. Di bagian hilir terdapat aktivitas perikanan dan lalu lintas perahu nelayan pencari ikan.

\subsection{Hasil Penelitian \\ 4.3.1 Kualitas Air Sungai Kaligarang}

Kualitas air Sungai Kaligarang sangat menentukan proses pengolahan dan biaya yang akan dikeluarkan oleh PDAM Tirta Moedal Semarang. Hasil dari pengambilan sampel sesuai titik yang telah ditentukan terdapat data dengan 3 titik yaitu di Tugu Suharto, belakang PDAM, dan muara Sungai Kaligarang. Pada data kualitas air, Laboratorium Cito dapat menghasilkan 29 parameter data kualitas air yang terbagi menjadi dua parameter secara fisika dan kimia. Parameter secara fisika yaitu suhu, zat padat terlarut dan zat padat tersuspensi. Parameter secara kimia terdapat 26 data yaitu:
1. $\mathrm{pH}$

2. Nitrit

3. Ammonia

4. Khromium

5. Sulfat

6. Besi

7. Mangan

8. Tembaga

9. Seng

10. Klorida

11. COD

12. BOD

13. Flourida

14. Nitrat

15. Arsen

16. Timbal

17. Kadrium

18. Selenium

19. Air raksa

20. Sianida

21. Sisa Klor

22. Sulfida

23. Detergen

24. Fenol

25. Fosfat

26. Minyak dan lemak

Tabel 1 Data Kualitas Air Berdasarkan Zona Pengamatan

\begin{tabular}{|c|c|c|c|c|c|c|c|}
\hline \multirow[b]{2}{*}{ No } & \multirow[b]{2}{*}{$\begin{array}{c}\text { PARA } \\
\text { METER }\end{array}$} & \multirow[b]{2}{*}{$\begin{array}{l}\text { SA } \\
\text { TU } \\
\text { AN }\end{array}$} & \multirow[b]{2}{*}{$\begin{array}{l}\text { PP No. } 82 \\
\text { Tahun } 2001 \\
\text { Kelas 1 }\end{array}$} & \multirow{2}{*}{$\begin{array}{l}\text { PP No. } 82 \\
\text { Tahun } \\
2001 \\
\text { Kelas } 2\end{array}$} & \multicolumn{3}{|c|}{ ZONA PENGAMATAN } \\
\hline & & & & & $\begin{array}{c}\text { TITIK } 1 \\
\text { TUGU } \\
\text { SUHARTO }\end{array}$ & $\begin{array}{c}\text { TITIK } 2 \\
\text { BELAKANG } \\
\text { PDAM }\end{array}$ & $\begin{array}{r}\text { TITIK } 3 \\
\text { MUARA }\end{array}$ \\
\hline \multicolumn{8}{|c|}{ FISIKA } \\
\hline 1 & Suhu & ${ }^{0} \mathrm{C}$ & deviasi 3 & deviasi 3 & 23.3 & 23.4 & 23.3 \\
\hline 2 & $\begin{array}{c}\text { Zat } \\
\text { Padat } \\
\text { Terlarut }\end{array}$ & $\begin{array}{l}\mathrm{mg} \\
/ \mathrm{L}\end{array}$ & 1000 & 1000 & 135 & 138 & 10000 \\
\hline 3 & $\begin{array}{c}\text { Zat } \\
\text { Padat } \\
\text { Tersusp } \\
\text { ensi }\end{array}$ & $\begin{array}{l}\mathrm{mg} \\
/ \mathrm{L}\end{array}$ & 50 & 50 & $<5$ & 27 & 406 \\
\hline \multicolumn{8}{|c|}{ KIMIA } \\
\hline 4 & $\mathrm{pH}$ & - & $6,0-9,0$ & $6,0-9,0$ & 9.3 & 8.8 & 7.9 \\
\hline 5 & $\begin{array}{c}\text { Nitrit } \\
\text { sebagai } \\
\mathrm{N}\end{array}$ & $\begin{array}{l}\mathrm{mg} \\
/ \mathrm{L}\end{array}$ & 0.06 & 0.06 & 0.07 & 0.08 & 0.13 \\
\hline
\end{tabular}




\begin{tabular}{|c|c|c|c|c|c|c|c|}
\hline 6 & $\begin{array}{c}\text { Ammo } \\
\text { nia }\end{array}$ & $\begin{array}{l}\mathrm{mg} \\
/ \mathrm{L}\end{array}$ & 0.5 & - & 0.11 & 0.1 & 1.03 \\
\hline 7 & $\begin{array}{c}\text { Chromi } \\
\text { um val. } \\
6\end{array}$ & $\begin{array}{l}\mathrm{mg} \\
/ \mathrm{L}\end{array}$ & 0.05 & 0.05 & 0,008 & 0,008 & 0,008 \\
\hline 8 & Sulfat & $\begin{array}{l}\mathrm{mg} \\
/ \mathrm{L}\end{array}$ & 400 & - & 25.8 & 25.2 & 1258 \\
\hline 9 & Besi & $\begin{array}{l}\mathrm{mg} \\
/ \mathrm{L}\end{array}$ & 0.3 & - & 0,07 & 0,07 & 0,07 \\
\hline 10 & $\begin{array}{c}\text { Manga } \\
\mathrm{n}\end{array}$ & $\begin{array}{l}\mathrm{mg} \\
/ \mathrm{L}\end{array}$ & 0.1 & - & 0,03 & 0,03 & 0.32 \\
\hline 11 & $\begin{array}{c}\text { Temba } \\
\text { ga }\end{array}$ & $\begin{array}{l}\mathrm{mg} \\
/ \mathrm{L}\end{array}$ & 0.02 & 0.02 & 0,01 & 0,01 & 0,01 \\
\hline 12 & Seng & $\begin{array}{l}\mathrm{mg} \\
/ \mathrm{L}\end{array}$ & 0.05 & 0.05 & 0.02 & 0.02 & 0.11 \\
\hline 13 & $\begin{array}{c}\text { Chlorid } \\
e\end{array}$ & $\begin{array}{l}\mathrm{mg} \\
/ \mathrm{L}\end{array}$ & 600 & - & 14 & 12 & 3970 \\
\hline 14 & COD & $\begin{array}{l}\mathrm{mg} \\
/ \mathrm{L}\end{array}$ & 10 & 25 & 16 & 13 & 187 \\
\hline 15 & BOD & $\begin{array}{l}\mathrm{mg} \\
/ \mathrm{L}\end{array}$ & 2 & 3 & 5 & 6 & 21 \\
\hline 16 & $\begin{array}{c}\text { Fluorid } \\
\text { a }\end{array}$ & $\begin{array}{l}\mathrm{mg} \\
/ \mathrm{L}\end{array}$ & 0.5 & 1.5 & 0.14 & 0.08 & 0.64 \\
\hline 17 & $\begin{array}{c}\text { Nitrat } \\
\text { sebagai } \\
\mathrm{N}\end{array}$ & $\begin{array}{c}\mathrm{mg} \\
/ \mathrm{L}\end{array}$ & 10 & 10 & 0.02 & 0 & 0 \\
\hline 18 & Arsen & $\begin{array}{l}\mathrm{mg} \\
/ \mathrm{L}\end{array}$ & 0.05 & 1 & 0,01 & 0,01 & 0,01 \\
\hline 19 & Timbal & $\begin{array}{l}\mathrm{mg} \\
/ \mathrm{L}\end{array}$ & 0.03 & 0.03 & 0,03 & 0,03 & 0,03 \\
\hline 20 & $\begin{array}{c}\text { Cadmiu } \\
m\end{array}$ & $\begin{array}{l}\mathrm{mg} \\
/ \mathrm{L}\end{array}$ & 0.01 & 0.01 & 0,006 & 0,006 & 0,006 \\
\hline 21 & $\begin{array}{c}\text { Seleniu } \\
\mathrm{m}\end{array}$ & $\begin{array}{l}\mathrm{mg} \\
/ \mathrm{L}\end{array}$ & 0.01 & 0.05 & 0,005 & 0,005 & 0,005 \\
\hline 22 & $\begin{array}{c}\text { Air } \\
\text { Raksa }\end{array}$ & $\begin{array}{l}\mathrm{mg} \\
/ \mathrm{L}\end{array}$ & 0.001 & 0.002 & 0,0002 & 0,0002 & 0,0002 \\
\hline 23 & Sianida & $\begin{array}{c}\mathrm{mg} \\
/ \mathrm{L}\end{array}$ & 0.02 & 0.02 & 0.0008 & 0.01 & 0.01 \\
\hline 24 & $\begin{array}{l}\text { Sisa } \\
\text { chlor }\end{array}$ & $\begin{array}{l}\mathrm{mg} \\
/ \mathrm{L}\end{array}$ & 0.03 & 0.03 & 0.19 & 0.17 & 0.22 \\
\hline 25 & Sulfide & $\begin{array}{l}\mathrm{mg} \\
/ \mathrm{L}\end{array}$ & 0.02 & 0.02 & 0,04 & 0,04 & 0,04 \\
\hline 26 & $\begin{array}{c}\text { Deterge } \\
n t\end{array}$ & $\begin{array}{c}\mu \mathrm{g} / \\
\mathrm{L}\end{array}$ & 200 & 200 & 69.6 & 54.9 & 220 \\
\hline 27 & Fenol & $\begin{array}{c}\mu \mathrm{g} / \\
\mathrm{L}\end{array}$ & 1 & 1 & 360 & 430 & 590 \\
\hline 28 & Fosfat & $\mathrm{mg}$ & 0.2 & 0.2 & 1.43 & 1.01 & 1.58 \\
\hline
\end{tabular}




\begin{tabular}{|c|c|c|c|c|c|c|c|} 
& & & & & \\
\hline 29 & $\begin{array}{c}\text { Minyak } \\
\& \\
\text { Lemak }\end{array}$ & $\mu \mathrm{L} /$ & 1000 & 1000 & 4000 & 3000 & 5000 \\
& & & & & & \\
\hline
\end{tabular}

Zona pengamatan memiliki beberapa parameter yang menunjukkan hasil yang stabil dan terjadi perubahan yang besar pada titik 3.

Dapat disimpulkan bahwa nilai parameter fisika maupun kimia pada titik 1 dan titik 2 kualitas air di daerah tersebut pada musim kemarau masih stabil dan tidak melebihi dari batas baku mutu yang ada dan dapat digunakan sebagai air baku PDAM Tirta Moedal Semarang. Pada titik 3 hasil uji kualitas air sangat buruk dan jauh melebihi dari batas baku mutu yang berlaku. Hal ini menunjukkan buruknya kualitas air yang berada di muara Sungai Kaligarang, meskipun PDAM Tirta Moedal Semarang tidak mengambil air baku dari daerah muara namun tidak ada salahnya apabila masyarakat tetap menjaga kualitas air Sungai Kaligarang dari hulu hingga hilir supaya tidak merusak ekosistem yang ada di daerah muara

\subsubsection{Pengolahan Air Baku di PDAM Tirta Moedal Semarang}

Pengolahan air baku dari Sungai Kaligarang dilakukan dengan berbagai tahap. Tahapan pengolahan air yang dilakukan oleh PDAM Tirta Moedal Semarang adalah sebagai berikut:

1. Bangunan Penangkap Air (intake) adalah bangunan untuk menangkap air dan mengumpulkan air dari suatu sumber. Bangunan ini dilengkapi dengan saringan sampah besar yang letaknya di depan saringan sedang guna menghambat sampah besar masuk ke dalam saringan sedang (bar screen).
Sampah yang lolos dengan saringan sampah besar akan disaring oleh saringan kasar (bar screen) tersebut untuk menangkap sampah yang berukuran sedang dan saringan halus (fine screen) untuk menghambat sampah yang berukuran kecil.

2. Bangunan Pengendapan Pertama yaitu bangunan untuk air yang telah masuk dalam bangunan penangkap air (intake) kemudian dibawa oleh pipa ke ruang pembentukan flok. Di dalam pipa tersebut kemudian dibubuhkan koagulan berupa CMA dan Khlorin melalui lubang injeksi dengan ukuran yang telah ditentukan oleh analis. Setelah air dibubuhkan koagulan, air dialirkan ke bangunan pengendap pertama. Dalam proses ini gumpalan flok akan turun atau mengendap sedangkan air akan naik.

3. Bangunan Pengendapan Kedua yaitu bangunan untuk air dari bangunan pengendapan pertama kemudian dibawa ke bangunan pengendap kedua, di tahap ini air dipisah dengan tube shelter untuk penyekat dan air yang tidak mengandung lumpur akan naik sedangkan flok akan turun di dasar tube shelter.

Flok atau endapan lumpur yang mengendap kemudian akan menuju ke kantong lumpur, dan ketinggian lumpur di kantong lumpur dikurangi dengan cara dilakukan pembuangan setiap 3 jam sekali supaya lumpur tidak memadat dan mengganggu kerja alat. Air dari proses ini kemudian akan dibawa ke saluran induk sebelum masuk ke dalam ruang filter. 
4. Ruang Filter yaitu ruang untuk air yang telah masuk ke dalam ruang filter kemudian air diendapkan kembali, kondisi air yang berada di ruang filter akan keruh dan berbusa pada permukaannya.

Air yang akan digunakan bukan air permukaan tapi hasil dari penyaringan di ruang filter, kemudian air hasil penyaringan dibawa menuju ruang media filter yang berisi pasir silika dan batu putih. Bagian dasar dari media filter merupakan batu putih dengan ukuran 3-5 cm kemudian ukuran 1-2 cm untuk lapisan kedua dan pasir silika urutan yang paling atas.

5. Bak Syphon merupakan bak pencucian media filter. Pencucian media filter dilakukan apabila filter tidak mampu melakukan penyaringan dengan baik.

6. Bukaan Valve untuk membuang lumpur yang telah mengendap di dalam ruang media filter.

7. Reservoir yaitu ruang air yang telah diberi desinfektan, yang merupakan tahap akhir dari proses pengolahan air baku menjadi air bersih dengan tujuan membunuh bakteri. Pada proses ini air yang mengalir dari media filter menuju ke reservoir kembali dibubuhkan chlorine yang bertujuan untuk membunuh mikroorganisme patogen.

Kemudian air yang berada di reservoir dialirkan pada pipa transmisi menuju ke pompa transport dan pompa distribusi. Pompa transport digunakan untuk mengirim air ke wilayah yang jauh sedangkan pompa distribusi digunakan untuk mengirim air ke lokasi terdekat.

Sebelum air olahan PDAM Tirta Moedal didistribusikan pada konsumen terlebih dahulu dilakukan uji laboratorium untuk mengecek bahwa air layak untuk dikomsumsi.
Tingginya kadar bahan pencemar pada Sungai Kaligarang tidak mempengaruhi pada proses produksi. PDAM Tirta Moedal Semarang menghentikan proses produksi pada saat kondisi air Sungai Kaligarang sangat keruh, kondisi air yang keruh biasanya dikarenakan hujan yang terjadi di daerah atas dan aliran sungai dari daerah atas membawa sedimen sehingga kondisi air menjadi keruh. Pada kondisi seperti ini proses produksi akan dihentikan selama 2 sampai 3 jam untuk menunggu kadar sedimen atau kekeruhan tersebut mengendap. Pada saat proses produksi dihentikan pasokan air yang akan didistribusikan tidak akan ada masalah apabila PDAM Tirta Moedal Semarang masih memiliki pasokan air yang cukup di bangunan reservoir. Namun apabila pasokan air di bangunan reservoir tidak mencukupi untuk didistribusikan kepada konsumen, otomatis suplai air bersih dari PDAM Tirta Moedal Semarang akan terganggu. Masyarakat sebaiknya memiliki tandon atau tempat penyimpanan air, jadi apabila PDAM Tirta Moedal Semarang menghentikan proses produksi masyarakat tidak kekurangan air.

\subsection{Kesimpulan}

Pemanfaatan air sungai, termasuk aliran air sungai perlu dilaksanakan secara bijaksana mengingat masyarakat yang terus membutuhkan air bersih untuk kegiatan sehari-hari. Klasifikasi kualitas air yang diatur berdasarkan PPRI Nomor 82 tahun 2001 menjadi acuan yang memperlihatkan kelayakan kualitas air Sungai Kaligarang sebagai air baku PDAM Tirta Moedal Semarang. Nilai parameter kualitas air yang sesuai dengan klasifikasi kualitas air sebagai air baku menyatakan bahwa kualitas air sungai tersebut layak untuk diolah 
PDAM. Nilai parameter yang tidak memenuhi syarat klasifikasi dapat memberi dampak bagi masyarakat. Kualitas air yang buruk dapat mempengaruhi kesehatan masyarakat dan proses pengolahan air di PDAM Tirta Moedal.

1. Berdasarkan hasil laboratorium uji kualitas air di titik 1 daerah Tugu Suharto air di daerah tersebut memiliki nilai $\mathrm{pH}$ sebesar 9,3, pada titik 2 nilai $\mathrm{pH}$ sebesar 8,8 dan nilai $\mathrm{pH}$ sebesar 7,9. Pada ketiga titik tersebut dapat dilihat bahwa titik 1 melebihi dari nilai ambang batas yang telah ditentukan yaitu sebesar 6,0-9,0 sedangkan pada titik 2 dan titik 3 masih di bawah nilai ambang batas.

2. Pada parameter zat padat terlarut hasil pada titik 1 sebesar $135 \mathrm{mg} / \mathrm{l}$, pada titik 2 sebesar $138 \mathrm{mg} / \mathrm{l}$ sedangkan pada titik 3 sebesar $10000 \mathrm{mg} / \mathrm{l}$. Dari data tersebut dapat dilihat bahwa titik 3 melebihi dari nilai ambang batas yang telah ditetapkan yaitu sebesar $10000 \mathrm{mg} / \mathrm{l}$.

3. Hasil uji kualitas air pada parameter sulfat menunjukkan hasil pada titik 1 sebesar 25,8 mg/l, pada titik 2 sebesar $25,2 \mathrm{mg} / \mathrm{l}$ dan titik 3 sebesar 1258 $\mathrm{mg} / \mathrm{l}$. Hasil tertinggi ada pada titik 3 dan nilai tersebut melebihi dari nilai ambang batas yang telah ditentukan yaitu sebesar $400 \mathrm{mg} / \mathrm{l}$.

4. Hasil uji parameter klorida menunjukkan hasil pada titik sebesar $14 \mathrm{mg} / \mathrm{l}$, titik 2 sebesar $12 \mathrm{mg} / \mathrm{l}$ sedangkan titik 3 sebesar $3970 \mathrm{mg} / \mathrm{l}$. Hasil tertinggi ada pada titik 3 dan hasil tersebut melebihi dari nilai ambang batas yang telah ditentukan yaitu sebesar $600 \mathrm{mg} / \mathrm{l}$.

5. Uji kualitas air pada parameter COD pada titik 1 menunjukkan hasil sebesar $16 \mathrm{mg} / \mathrm{l}$, pada titik 2 sebesar $13 \mathrm{mg} / \mathrm{l}$ sedangkan pada titik 3 sebesar $187 \mathrm{mg} / \mathrm{l}$. Nilai ambang batas sebesar $25 \mathrm{mg} / \mathrm{l}$, dapat disimpulkan bahwa hasil dari ketiga titik tersebut melebihi dari nilai ambang batas yang telah ditentukan.

6. Hasil uji kualitas air parameter BOD pada titik 1 menunjukkan hasil sebesar $5 \mathrm{mg} / \mathrm{l}$, pada titik 2 sebesar 6 $\mathrm{mg} / \mathrm{l}$ sedangkan pada titik 3 sebesar $21 \mathrm{mg} / \mathrm{l}$. Hasil dari ketiga titik tersebut melebihi dari nilai ambang batas yang telah ditentukan yaitu sebesar $3 \mathrm{mg} / \mathrm{l}$.

7. Hasil uji kualitas air pada parameter fenol pada titik 1 sebesar $360 \mathrm{mg} / \mathrm{l}$, pada titik 2 sebesar $430 \quad \mathrm{mg} / \mathrm{l}$ sedangkan pada titik 3 sebesar 590 $\mathrm{mg} / \mathrm{l}$. Parameter fenol memiliki nilai ambang batas sebesar $1 \mathrm{mg} / \mathrm{l}$. dapat disimpulkan bahwa hasil dari ketiga titik tersebut melebihi nilai ambang batas.

8. Sumber pencemar air Sungai Kaligarang yaitu limbah rumah tangga dan limbah industri yang dibuang dan dialirkan pada aliran Sungai Kaligarang.

9. Penetralisir yang digunakan untuk proses pengolahan air baku PDAM Tirta Moedal Semarang yaitu chlorin dan tawas cair.

\subsection{Saran}

Dari penelitian ini saran yang dapat diberikan antara lain:

1. Instansi pemerintah meningkatkan kesadaran masyarakat akan pentingnya menjaga kualitas air Sungai Kaligarang dengan melakukan penyuluhan di kelurahan-kelurahan.

2. PDAM Tirta Moedal Semarang harus rutin melakukan pengecekkan air Sungai Kaligarang yang akan masuk ke dalam intake supaya mengetahui kualitas air dan dapat memberi langkah pengolahan yang tepat.

3. PDAM dapat memberi bantuan sosial berupa membuatkan sumur resapan untuk menampung air supaya tidak tercemar oleh bahan pencemar yang 
mencemari Sungai Kaligarang, karena hal ini dapat mengurangi beban kerja dari PDAM Tirta Moedal Semarang.

4. Masyarakat perlu menjaga kualitas air Sungai Kaligarang dengan memberikan saringan pada saluran selokan sebelum ke sungai supaya kualitas air Sungai Kaligarang tetap terjaga karena air Sungai Kaligarang merupakan air baku bagi PDAM Tirta Moedal Semarang.

5. Masyarakat harus bijaksana dalam memanfaatkan air maupun aliran air Sungai Kaligarang. Pabrik-pabrik industri juga seharusnya memiliki pengolahan limbah sehingga tidak menambah beban pencemar Sungai Kaligarang, jadi limbah yang dibuang pada Sungai Kaligarang merupakan limbah yang sudah diolah dan tidak merusak kualitas air dari Sungai Kaligarang tersebut.

\section{Daftar Pustaka}

Alaudin. (2016). Pengertian dan Klasifikasi Air.

http://www.amuzigi.com/2016/02/Penge rtian-dan-Klasifikasi-Kualitas-

Air.html. Diunduh pada 25 Juni 2018, pukul 15.51 WIB.

Ambarwati, Pragita Dyah. (2014). Kajian Kualitas Air Tanah di Sekitar Kawasan Budidaya Ikan pada Keramba Jaring Apung di Waduk Jatiluhur Kabupaten Purwakarta. Universitas Pendidikan Indonesia. http://repository.upi.edu/5818/4/S_ GEO_0907392_Chapter1.pdf. Diunduh pada tanggal 04 Juni 2018, pukul 22.52 WIB.

Dewajati (2013). Pengaruh Perubahan Penggunaan Lahan DAS Kaligarang terhadap Banjir di Kota Semarang. http://eprints.undip.ac.id/11386/1/20 03MTPK2922.pdf. Diunduh pada 21 Agustus 2018, pukul 22.11 WIB.

Company Profile PDAM Tirta Moedal. (2016). Www.pdamkotasmg.co.id
Effendi, H. (2003). Telaah Kualitas Air. Yogyakarta: Kanisius.

Fatahilah. (2013). Kajian Keterpaduan Pengelolaan Daerah Aliran Sungai (DAS)

Garang Provinsi Jawa Tengah. Jurnal Geografi Volume 10 No. 2 Juli 2013: 136-153. https://journal.unnes.ac.id/nju/index. php/JG/article/viewFile/8058/5585. Diunduh pada 14 Agustus 2018, pukul 20.30 WIB.

Hartono, D. (2005). Alternatif Pemenuhan Air Bersih Oleh PDAM di Kota Semarang. http://eprints.undip.ac.id/14650/1/20 05MTPWK3962.pdf. Diunduh pada 25 Juni 2018, pukul 16.51 WIB.

Kodoatie, Robert J., R. S. (2005). Pengelolaan Sumber Daya Air Terpadu.Yogyakarta: Andi.

Marlena.B, Setia Budi Sasongko, dan Danny Sutrisnanto. (2012). Kajian Pengelolaan DAS Garang Untuk Memenuhi Kualitas Air Sesuai Dengan Peruntukannya. https://core.ac.uk/download/pdf/117 34961.pdf. Diunduh pada tanggal 26 September 2018, pukul 11.05WIB.

Mulyanto. (2007). Sungai Fungsi dan Sifat-sifatnya.Yogyakarta Graha Ilmu.

Peraturan Pemerintah Republik Indonesia Nomor 20 Tahun 1990. Pengendalian Pencemaran Air. http://water.lecture.ub.ac.id/files/20 12/03/2.-PP-no-20-thn-1990-ttgPengendalian-Ppencemaran-AirThn-1990.pdf. Diunduh pada 29 Mei 2018, pukul 19.02 WIB.

Peraturan Pemerintah Republik Indonesia no.35 Tahun 1991. Sungai.

https://www.google.com/url?sa=t\&rct=j $\& \mathrm{q}=\&$ esrc $=\mathrm{s} \&$ source $=$ web $\& \mathrm{~cd}=1 \&$ $\mathrm{cad}=\mathrm{rja} \&$ uact $=8 \&$ ved $=2$ ahUKEwim sNi1zvDcAhXFJ8AKHTY9D3kQFj AAegQIAhAC\&url=http $\% 3 \mathrm{~A} \% 2 \mathrm{~F}$ 
\%2Fsda.pu.go.id\%3A8183\%2Fpand uan\%2Funduh-referensiperaturan\%2FPP_35_1991.pdf\&usg =AOvVaw0Zs3gnPwMURAFI_V4

ToyE1. Diunduh pada tanggal 05 Juni 2018, pukul 01.12 WIB.

Peraturan Pemerintah Repubik Indonesia Nomor 82 Tahun 2001. Pengelolaan Kualitas Air Baku dan Pengelolaan Pencemaran Air. http://pelayanan.jakarta.go.id/downl oad/regulasi/peraturan-pemerintahnomor-82-tahun-2001-tentangpengelolaan-kualitas-air-danpengendalian-pencemaran-air.pdf. Diunduh pada 29 Mei 2018, pukul 20.22 WIB.

Sari, M. (2016). Pencemaran Air: Pengertian, Sumber, Jenis, dan Akibat.

http://repository.usu.ac.id/bitstream/hand le/123456789/46582/Chapter\%20II. pdf? sequence $=3 \&$ is Allowed $=y$.

Diunduh pada 29 Mei 2018, pukul 19.37 WIB.

Setyowati. (2008). Antisipasi Penduduk dalam menghadapi Banjir Kali Garang Kota Semarang. Forum Ilmu Sosial, Vol.35 No. 2 Desember 2008.

https://journal.unnes.ac.id/nju/index.php/ FIS/article/viewFile/1294/1343.

Diunduh pada 21 Agustus 2018, pukul 21.42 WIB.

SNI 6674. (2008). Tata Cara Perencanaan Unit Paket Instalasi Pengolahan Air. Badan Standarisasi Nasional.

Sutrisno, C. T., dan Suciastuti, E. (2010). Teknologi Penyediaan Air Bersih. Jakarta: PT RINEKA CIPTA.

Windansari, Nini Dewi. (2013). Perlakuan Akuntansi atas PPH Pasal 21 pada PT. Artha Prima Finance Kotamobagu.

http://download.portalgaruda.org/art icle.php? article $=108829 \& \mathrm{val}=1025$ $\&$ title=PERLAKUAN\%20AKUNT
ANSI\%20ATAS\%20PPH\%20PAS AL\%2021\%20PADA\%20PT.\%20A RTHA\%20PRIMA\%20FINANCE\% 20KOTAMOBAGU. Diunduh pada 1 Juli 2018, pukul 23.42 WIB.

Windarta, J. (2009). Pengembangan Sistem Peringatan Dini Banjir Kali Garang Semarang dengan Teknologi Innformasi Berbasis SMS dan WEB. https://repository.ipb.ac.id/jspui/bitst ream/123456789/40568/3/Bab\%20I _2009jwi.pdf . Diunduh pada 21 Agustus 2018, pukul 21.34 WIB.

Yulia (2015). 15 Jenis Jenis Air di Muka Bumi : Tanah, Permukaan, Air Angkasa, dan Manfaatnya. https://ilmugeografi.com/ilmubumi/hidrologi/jenis-jenis-air.

Diunduh pada 29 Juni 2018, pukul 13.22 WIB.

Yulianti, Dwi dan Sunardi. (2010). Identifikasi Pencemaran Logam pada Sungai Kaligarang dengan Metode Analisis Aktivasi Netron Cepat (AANC). https://journal.unnes.ac.id/nju/index. $\mathrm{php} /$ sainteknol/article/view/336/0 Diunduh pada 22 Maret 2018, pukul 21.03 WIB. 